\title{
New fixed-disc results via bilateral type contractions on $S$-metric spaces
}

\author{
Nihal TAŞ ${ }^{1, *}$ \\ ${ }^{1}$ Ballkesir University, Faculty of Arts and Sciences,Department of Mathematics, Cagis Campus, Balikesir. \\ Geliş Tarihi (Received Date): 14.09 .2021 \\ Kabul Tarihi (Accepted Date): 24.12.2021
}

\begin{abstract}
There are some examples of self-mappings which does not satisfy the Banach contractive condition and have a unique fixed point or more than one fixed point. In this case, metric fixed-point theory has been extensively generalized using some techniques. One of these techniques is to generalize the used contractive conditions such as the Jaggi type contractive condition, the Dass-Gupta type contractive condition etc. Another technique is to generalize the used metric spaces such as a b-metric space, an S-metric space etc. The last technique is to investigate geometric properties of the fixed-point set of a given self-mapping such as fixed circle, fixed disc etc. For this purpose, "fixed-circle problem" has been studied with various techniques as a geometrical generalization of the metric fixed-point theory. This problem was also considered as "fixed-figure problem". Some solutions to these recent problems were obtained using different contractions both a metric space and a generalized metric space. The main purpose of this paper is to prove some fixed-disc theorems on an $S$ metric space. To do this, we modify the known contractive conditions. Also, the obtained new theorems are supported by some illustrative examples.
\end{abstract}

Keywords: Fixed disc, fixed circle, bilateral type contraction, S-metric space, fixedcircle problem

\section{S-metrik uzaylarda ikili tipinde daralmalar yardımıyla yeni sabit- disk sonuçları}

$\ddot{\mathbf{O z}}$

Banach daralma koşulunu sağlamayan ve bir tek sabit noktası ya da birden fazla sabit noktası olan fonksiyon örnekleri mevcuttur. Bu durumda, metrik sabit-nokta teorisi bazı

\footnotetext{
*Nihal TAŞ, nihaltas@balikesir.edu.tr, https://orcid.org/0000-0002-4535-4019
} 
teknikler kullanılarak kapsamlı olarak genelleştirilmektedir. Bu tekniklerden biri Jaggi tipinde daralma koşulu, Dass-Gupta tipinde daralma koşulu gibi kullanılan daralma koşulunun genelleştirilmesidir. Diğer bir teknik ise b-metrik uzay, S-metrik uzay gibi kullanılan metrik uzayın genelleştirilmesidir. Son teknik ise sabit çember, sabit disk gibi verilen bir fonksiyonun sabit nokta kümesinin geometrik özelliklerinin incelenmesidir. Bu amaç için, "sabit-çember problemi" metrik sabit-nokta teorisinin geometrik bir genellemesi olarak çeşitli tekniklerle çalışılmaktadır. Bu problem ayrica "sabit-figür problemi" olarak da düşünülebilir. Bu son problemlere bazı çözümler hem metrik uzaylar üzerinde hem de genelleştirilmiş metrik uzaylar üzerinde farkl daralmalar kullanılarak elde edilmiştir. Bu makalenin ana amacı S-metrik uzaylar üzerinde bazı sabit-disk teoremleri ispatlamaktır. Bunun için, Bunun için bilinen bazı daralma koşullarını modifiye edeceğiz. Ayrıca elde edilen bu yeni teoremleri bazı gerçekleyici örnekler ile destekleyeceğiz.

Anahtar kelimeler: Sabit disk, sabit çember, ikili tipinde daralma, S-metrik uzay, sabit çember problemi

\section{Introduction}

Fixed-point theory has been extensively studied with various aspects in mathematics since then the Banach contraction principle [1]. This principle guarantees that a selfmapping $f$ has a unique fixed point. To do this, some fixed-point theorems, which say that a function $f$ has at least one fixed point under appropriate conditions, have been proved. This theory has been generalized with different approaches as follows:

- To generalized the used contractive conditions,

- To generalize the used metric spaces,

- To investigate the geometric properties of the fixed point set of a self-mapping when the number of fixed points is more than one.

The notion of an $S$-metric was defined in [2] as follows:

\subsection{Definition [2]}

Let $U$ be a nonempty set and $S: U \times U \times U \rightarrow[0, \infty)$ a function. If $S$ satisfies the following conditions for all $\xi, \alpha, \beta, \gamma \in U$ :

(S1) $S(\xi, \alpha, \beta)=0 \Leftrightarrow \xi=\alpha=\beta$,

(S2) $S(\xi, \alpha, \beta) \leq S(\xi, \xi, \gamma)+S(\alpha, \alpha, \gamma)+S(\beta, \beta, \gamma)$,

then $S$ is called an $S$-metric on $U$ and the pair $(U, S)$ is called an $S$-metric space.

\subsection{Lemma [2]}

Let $(U, S)$ be an $S$-metric space and $\xi, \alpha \in U$. Then we have

$S(\xi, \xi, \alpha)=S(\alpha, \alpha, \xi)$.

In the following theorem, we see that the relationship between a $b$-metric [3] and an $S$ metric. 


\subsection{Theorem [4]}

Let $(U, S)$ be an $S$-metric space and

$d^{S}(\xi, \alpha)=S(\xi, \xi, \alpha)$.

Then $d^{S}$ is a $b$-metric on $U$.

The fixed-circle problem was introduced as a geometric generalization of fixed-point theory in [5]. After then, this problem has been studied with new aspects on $S$-metric spaces (for example, see [6],_[7], [8] and [9]).

Now we recall the following notions defined in [2], [6] and [8].

Let $(U, S)$ be an $S$-metric space and $f: U \rightarrow U$ a self-mapping. A circle $C_{\xi_{0}, \rho}^{S}$ and a disc $D_{\xi_{0}, \rho}^{S}$ are defined by

$C_{\xi_{0}, \rho}^{S}=\left\{\xi \in U: S\left(\xi, \xi, \xi_{0}\right)=\rho\right\}$

and

$D_{\xi_{0}, \rho}^{S}=\left\{\xi \in U: S\left(\xi, \xi, \xi_{0}\right) \leq \rho\right\}$

with the center $\xi_{0} \in U$ and the radius $\rho \geq 0$.

If $f \xi=\xi$ for all $\xi \in C_{\xi_{0}, \rho}^{S}$ (resp. $\xi \in D_{\xi_{0}, \rho}^{S}$ ) then the circle $C_{\xi_{0}, \rho}^{S}$ (resp. the disc $D_{\xi_{0}, \rho}^{S}$ ) is called as the fixed circle (resp. the fixed disc) of $f$.

We give the following example:

\subsection{Example}

Let $U=\mathbb{R}$ be the $S$-metric space with the $S$-metric $S: U \times U \times U \rightarrow[0, \infty)$ defined as

$S(\xi, \alpha, \beta)=|\xi-\beta|+|\xi+\beta-2 \alpha|$

for all $\xi, \alpha, \beta \in \mathbb{R}[10]$. If we define the self-mapping $f: \mathbb{R} \rightarrow \mathbb{R}$ as

$f \xi=\xi^{2}$,

for all $\xi \in \mathbb{R}$. Then we get the fixed-point set of $f$ such as

$\operatorname{Fix}(f)=\{0,1\}$.

Consequently, the self-mapping $f$ fixes the circle $C_{1 / 2,1}^{S}$ as seen in Figure 1 drawn by Mathematica [11]. 


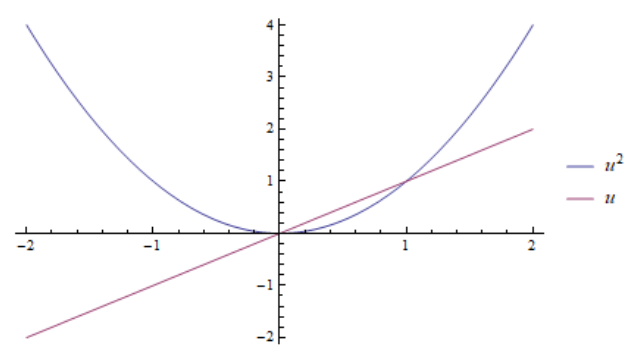

Figure 1. A self-mapping $f \xi=\xi^{2}$ with two fixed points 0 and 1 .

From the above motivations, in this paper, we investigate new fixed-disc results on $S$ metric spaces modifying some contractive conditions in the literature such as Jaggi type and Dass-Gupta type contractions introduced in [12] and [13]. The obtained results are supported by two illustrative examples. Also, we discuss some corollaries related to the obtained theoretical results. Thanks to the obtained theorems, new results will be brought to the literature on the geometry of fixed points.

\section{Main results}

In this section, we give new solutions to the "Fixed-Circle Problem" on $S$-metric spaces.

Let $f: U \rightarrow U$ be a self-mapping, $\psi: U \rightarrow[0, \infty)$ a function and

$$
F i x(f)=\{\xi \in U: f \xi=\xi\}
$$

the fixed-point set of the self-mapping $f$. Suppose that the number $\rho$ is defined as

$$
\rho:=\inf \left\{\frac{S(f \xi, f \xi, \xi)}{\psi(\xi)}: \xi \in U \text { and } \xi \notin F i x(f)\right\} \text {, }
$$

where $\psi(\xi)>0$ for all $\xi \in U-F i x(f)$.

Let us begin the following fixed-disc theorem.

\subsection{Theorem}

Let $(U, S)$ be an $S$-metric space, $f: U \rightarrow U$ a self-mapping and $\rho$ defined as in (1). Assume that there are a function $\psi: U \rightarrow[0, \infty)$ and $\xi_{0} \in U$ such that

$$
\xi \notin F i x(f) \Rightarrow S(f \xi, f \xi, \xi) \leq[\psi(\xi)-\psi(f \xi)] R_{f}^{S}\left(\xi_{0}, \xi\right)
$$

for all $\xi \in U-\left\{\xi_{0}\right\}$, where

$$
R_{f}^{S}(\xi, \alpha)=\max \left\{S(\xi, \xi, \alpha), \frac{S(f \xi, f \xi, \xi) S(f \alpha, f \alpha, \alpha)}{S(\xi, \xi, \alpha)}\right\}
$$

If $f \xi_{0}=\xi_{0}$, then we have $D_{\xi_{0}, \rho}^{S} \subseteq F i x(f)$, especially $C_{\xi_{0}, \rho}^{S} \subseteq F i x(f)$. 


\section{Proof}

Let $\rho=0$. Then we have $C_{\xi_{0}, \rho}^{S}=D_{\xi_{0}, \rho}^{S}=\left\{\xi_{0}\right\}$ and using the hypothesis $f \xi_{0}=\xi_{0}$, we get $D_{\xi_{0}, \rho}^{S} \subseteq \operatorname{Fix}(f)$ and $C_{\xi_{0}, \rho}^{S} \subseteq \operatorname{Fix}(f)$.

Let $\rho>0$ and $\xi \in D_{\xi_{0}, \rho}^{S}$ be any point such that $\xi \notin F i x(f)$. Using the inequality (2) and Lemma 1.2, we obtain

$$
\begin{aligned}
S(f \xi, f \xi, \xi) \leq[\psi(\xi)-\psi(f \xi)] R_{f}^{S}\left(\xi_{0}, \xi\right) & =[\psi(\xi)-\psi(f \xi)] S\left(\xi_{0}, \xi_{0}, \xi\right) \\
= & {[\psi(\xi)-\psi(f \xi)] S\left(\xi, \xi, \xi_{0}\right) \leq[\psi(\xi)-\psi(f \xi)] \rho }
\end{aligned}
$$

and by the definition of $\rho$, we get

$S(f \xi, f \xi, \xi) \leq[\psi(\xi)-\psi(f \xi)] \frac{S(f \xi, f \xi, \xi)}{\psi(\xi)}<S(f \xi, f \xi, \xi)$

a contradiction. It should be $\xi \in F i x(f)$.

Consequently, we have $D_{\xi_{0}, \rho}^{S} \subseteq \operatorname{Fix}(f)$, especially $C_{\xi_{0}, \rho}^{S} \subseteq$ Fix $(f)$.

\subsection{Example}

$U=\mathbb{R}$ be the $S$-metric space with the $S$-metric defined as in Example 1.4. Let us define the self-mapping $f: \mathbb{R} \rightarrow \mathbb{R}$ as

$$
f \xi=\left\{\begin{array}{lll}
\xi & \text { if } & \xi \in[-2,2] \\
0 & \text { if } & \xi \notin[-2,2]
\end{array},\right.
$$

for all $\xi \in \mathbb{R}$. Then $f$ satisfies the conditions of Theorem 2.1 with $\xi_{0}=0$ and the function $\psi: \mathbb{R} \rightarrow[0, \infty)$ defined as

$$
\psi(\xi)=\left\{\begin{array}{ccc}
\frac{1}{2} & \text { if } & \xi \in[-2,2] \\
|\xi| & \text { if } & \xi \notin[-2,2]
\end{array},\right.
$$

for all $\xi \in \mathbb{R}$. Also, we get

$$
\rho=\inf \left\{\frac{S(f \xi, f \xi, \xi)}{\psi(\xi)}: \xi \in \mathbb{R} \text { and } \xi \notin F i x(f)\right\}=\inf \left\{\frac{2|\xi|}{|\xi|}: \xi \in \mathbb{R}-[-2,2]\right\}=2 \text {. }
$$

Consequently, $C_{0,2}^{S}=\{-1,1\} \subset \operatorname{Fix}(f)=[-2,2]$ and $D_{0,2}^{S}=[-1,1] \subset F i x(f)=[-2,2]$. In other words, $D_{0,2}^{S}$ (resp. $C_{0,2}^{S}$ ) is a fixed disc (resp. fixed circle) of the self-mapping $f$. 


\subsection{Theorem}

Let $(U, S)$ be an $S$-metric space, $f: U \rightarrow U$ a self-mapping and $\rho$ defined as in (1). Assume that there are a function $\psi: U \rightarrow[0,1)$ and $\xi_{0} \in U$ such that

$\xi \notin F i x(f) \Rightarrow S(f \xi, f \xi, \xi) \leq[\psi(\xi)-\psi(f \xi)] Q_{f}^{S}\left(\xi_{0}, \xi\right)$,

for all $\xi \in U-\left\{\xi_{0}\right\}$, where

$$
Q_{f}^{S}(\xi, \alpha)=\max \left\{S(\xi, \xi, \alpha), \frac{(1+S(f \xi, f \xi, \xi)) S(f \alpha, f \alpha, \alpha)}{1+S(\xi, \xi, \alpha)}\right\} .
$$

If $f \xi_{0}=\xi_{0}$, then we have $D_{\xi_{0}, \rho}^{S} \subseteq \operatorname{Fix}(f)$, especially $C_{\xi_{0}, \rho}^{S} \subseteq \operatorname{Fix}(f)$.

\section{Proof}

Let $\rho=0$. Then we have $C_{\xi_{0}, \rho}^{S}=D_{\xi_{0}, \rho}^{S}=\left\{\xi_{0}\right\}$ and using the hypothesis $f \xi_{0}=\xi_{0}$, we get

$$
D_{\xi_{0}, \rho}^{S} \subseteq \operatorname{Fix}(f) \text { and } C_{\xi_{0}, \rho}^{S} \subseteq \operatorname{Fix}(f)
$$

Let $\rho>0$ and $\xi \in D_{\xi_{0}, \rho}^{S}$ be any point such that $\xi \notin F i x(f)$. Using the inequality (3) and Lemma 1.2, we obtain

$$
\begin{aligned}
S(f \xi, f \xi, \xi) & \leq[\psi(\xi)-\psi(f \xi)] Q_{f}^{S}\left(\xi_{0}, \xi\right) \\
& =[\psi(\xi)-\psi(f \xi)] \max \left\{S\left(\xi_{0}, \xi_{0}, \xi\right), \frac{S(f \xi, f \xi, \xi)}{1+S\left(\xi_{0}, \xi_{0}, \xi\right)}\right\} \\
& <\psi(\xi) \max \left\{\rho, \frac{S(f \xi, f \xi, \xi)}{1+S\left(\xi_{0}, \xi_{0}, \xi\right)}\right\} \\
& \leq \psi(\xi) \max \left\{\frac{S(f \xi, f \xi, \xi)}{\psi(\xi)}, \frac{S(f \xi, f \xi, \xi)}{1+S\left(\xi_{0}, \xi_{0}, \xi\right)}\right\}=S(f \xi, f \xi, \xi)
\end{aligned}
$$

a contradiction. It should be $\xi \in F i x(f)$.

Consequently, we have $D_{\xi_{0}, \rho}^{S} \subseteq \operatorname{Fix}(f)$, especially $C_{\xi_{0}, \rho}^{S} \subseteq$ Fix $(f)$.

\subsection{Example}

$U=\left\{-\frac{7}{2},-3,-\frac{3}{2},-\frac{3}{4}, 0, \frac{3}{4}, \frac{3}{2}, 3, \frac{7}{2}\right\}$ be the $S$-metric space with the $S$-metric defined as in Example 1.4. Let us define the self-mapping $f: U \rightarrow U$ as

$$
f \xi=\left\{\begin{array}{ccc}
\xi & \text { if } & \xi \in U-\{3\} \\
\xi+\frac{1}{2} & \text { if } & \xi=3
\end{array},\right.
$$


for all $\xi \in U$. Then $f$ satisfies the conditions of Theorem 2.3 with $\xi_{0}=0$ and the function $\psi: U \rightarrow[0,1)$ defined as

$\psi(\xi)=\left\{\begin{array}{llc}\frac{1}{3} & \text { if } & \xi \in U-\{3\} \\ \frac{2}{3} & \text { if } & \xi=3\end{array}\right.$,

for all $\xi \in U$. Also, we get

$\rho=\inf \left\{\frac{S(f \xi, f \xi, \xi)}{\psi(\xi)}: \xi \in U\right.$ and $\left.\xi \notin F i x(f)\right\}=\inf \left\{\frac{1}{\frac{2}{3}}: \xi=3\right\}=\frac{3}{2}$.

Consequently, we have

$C_{0,3 / 2}^{S}=\left\{-\frac{3}{4}, \frac{3}{4}\right\} \subset F i x(f)=U-\{3\}$ and $D_{0,3 / 2}^{S}=\left\{-\frac{3}{4}, 0, \frac{3}{4}\right\} \subset F i x(f)=U-\{3\}$.

In other words, $D_{0,3 / 2}^{S}$ (resp. $C_{0,3 / 2}^{S}$ ) is a fixed disc (resp. fixed circle) of the self-mapping $f$.

As a consequences of Theorem 2.1 and Theorem 2.3, we get the following corollary.

\subsection{Corollary}

Let $(U, S)$ be an $S$-metric space, $f: U \rightarrow U$ a self-mapping and $\rho$ defined as in (1). Suppose that one of the following conditions is satisfied.

(a) There are a function $\psi: U \rightarrow[0, \infty)$ and $\xi_{0} \in U$ such that

$$
\begin{aligned}
\xi \notin F i x(f) \Rightarrow & S(f \xi, f \xi, \xi) \\
& \leq[\psi(\xi)-\psi(f \xi)]\left(a_{1} S\left(\xi, \xi, \xi_{0}\right)+a_{2} \frac{S(f \xi, f \xi, \xi) S\left(f \xi_{0}, f \xi_{0}, \xi_{0}\right)}{S\left(\xi, \xi, \xi_{0}\right)}\right),
\end{aligned}
$$

for all $\xi \in U-\left\{\xi_{0}\right\}$, where $a_{1}, a_{2}$ are two nonnegative real numbers with a sum 1 .

(b) There are a function $\psi: U \rightarrow[0, \infty)$ and $\xi_{0} \in U$ such that

$$
\begin{aligned}
\xi \notin F i x(f) \Rightarrow & S(f \xi, f \xi, \xi) \\
& \leq[\psi(\xi)-\psi(f \xi)]\left(a_{1} S\left(\xi, \xi, \xi_{0}\right)+a_{2} \frac{(1+S(f \xi, f \xi, \xi)) S\left(f \xi_{0}, f \xi_{0}, \xi_{0}\right)}{1+S\left(\xi, \xi, \xi_{0}\right)}\right),
\end{aligned}
$$


for all $\xi \in U-\left\{\xi_{0}\right\}$, where $a_{1}, a_{2}$ are two nonnegative real numbers with a sum 1 .

(c) There are a function $\psi: U \rightarrow[0, \infty)$ and $\xi_{0} \in U$ such that

$\xi \notin F i x(f) \Rightarrow S(f \xi, f \xi, \xi) \leq[\psi(\xi)-\psi(f \xi)] S\left(\xi, \xi, \xi_{0}\right)$,

for all $\xi \in U-\left\{\xi_{0}\right\}$.

(d) There are a function $\psi: U \rightarrow[0,1)$ and $\xi_{0} \in U$ such that

$$
\begin{aligned}
\xi \notin \operatorname{Fix}(f) \Rightarrow & S(f \xi, f \xi, \xi) \\
& \leq[\psi(\xi)-\psi(f \xi)]\left(\frac{\left(1+S\left(f \xi_{0}, f \xi_{0}, \xi_{0}\right)\right) S(f \xi, f \xi, \xi)}{1+S\left(\xi, \xi, \xi_{0}\right)}\right),
\end{aligned}
$$

for all $\xi \in U-\left\{\xi_{0}\right\}$.

If $f \xi_{0}=\xi_{0}$, then we have $D_{\xi_{0}, \rho}^{S} \subseteq \operatorname{Fix}(f)$, especially $C_{\xi_{0}, \rho}^{S} \subseteq \operatorname{Fix}(f)$.

\section{Proof}

From the similar arguments used in the proofs of Theorem 2.1 and Theorem 2.3, it can be easily proved using the numbers $R_{f}^{S}(\xi, \alpha)$ and $Q_{f}^{S}(\xi, \alpha)$.

\subsection{Remark}

(i) Theorem 2.1 can be considered as a Jaggi type fixed-disc (or fixed-circle) theorem and Theorem 2.3 can be considered as a Dass-Gupta type fixed-disc (or fixed-circle) theorem.

(ii) If we consider Theorem 1.3, then we obtain new fixed-disc (or fixed-circle) results using the similar techniques given in Theorem 2.1 (resp. Theorem 2.3 and Corollary 2.5) on $b$-metric spaces.

(iii) It is clear that $R_{f}^{S}\left(\xi_{0}, \xi\right)=R_{f}^{S}\left(\xi, \xi_{0}\right)$ but $Q_{f}^{S}\left(\xi_{0}, \xi\right) \neq Q_{f}^{S}\left(\xi, \xi_{0}\right)$.

(iv) The investigating new fixed-disc (or fixed-circle) results on $S$-metric spaces is important because there are some examples of an $S$-metric which is not generated by any metric (for more details, see [10]).

\section{Conclusion}

In this paper, we obtain new fixed-disc results using the Jaggi type and Dass-Gupta type contractions on $S$-metric spaces. Using the similar approaches, some solutions to the fixed-figure problem given in [14] can be investigated. Therefore, new results will be gained to the geometry of the fixed-point theory. 


\section{References}

[1] Banach, S., Sur les operations dans les ensembles abstraits et leur application aux equations integrals, Fundamenta Mathematicae, 2, 133-181, (1922).

[2] Sedghi, S., Shobe, N. ve Aliouche, A., A generalization of fixed point theorems in $S$-metric spaces, Matematički Vesnik, 64, 3, 258-266, (2012).

[3] Bakhtin, I. A., The contraction principle in quasimetric spaces, Functional Analysis, 30, 26-37, (1989).

[4] Sedghi, S. ve Dung, N. V., Fixed point theorems on $S$-metric spaces, Matematički Vesnik, 66, 1, 113-124, (2014).

[5] Özgür, N. Y. ve Taş, N., Some fixed-circle theorems on metric spaces, Bulletin of the Malaysian Mathematical Sciences Society, 42, 4, 1433-1449, (2019).

[6] Mlaiki, N., Çelik, U., Taş, N., Özgür, N. Y. ve Mukheimer, A., Wardowski type contractions and the fixed-circle problem on $S$-metric spaces, Journal of Mathematics, 9, (2018).

[7] Özgür, N. Y., Taş, N. ve Çelik, U., New fixed-circle results on $S$-metric spaces. Bulletin of Mathematical Analysis and Applications, 9, 2, 10-23, (2017).

[8] Özgür, N. Y. and Taş, N., Fixed-circle problem on $S$-metric spaces with a geometric viewpoint, Facta Universitatis. Series: Mathematics and Informatics, 34, 3, 459-472, (2019).

[9] Taş, N. ve Özgür, N., On the geometry of fixed points for self-mappings on $S$ metric spaces, Communications Faculty of Sciences University of Ankara Series A1-Mathematics and Statistics, 69, 2, 190-198, (2020).

[10] Özgür, N. Y. ve Taş, N., Some new contractive mappings on $S$-metric spaces and their relationships with the mapping (S25), Mathematical Sciences, 11, 1, 7-16, (2017).

[11] Wolfram Research, Inc., Mathematica, Version 12.0, Champaign, IL (2019).

[12] Chen, C. M., Joonaghany, G. H., Karapınar, E. ve Khojasteh, F., On bilateral contractions, Mathematics, 7, 38, (2019).

[13] Taş, N., Bilateral-type solutions to the fixed-circle problem with rectified linear units application, Turkish Journal of Mathematics, 44, 4, 1330-1344, (2020).

[14] Özgür, N. Y. ve Taş, N., Geometric properties of fixed points and simulation functions, arXiv:2102.05417, (2021). 